\title{
CKD-EPI Creatinine-Cystatin C Formula
}

National Cancer Institute

\section{Source}

National Cancer Institute. CKD-EPI Creatinine-Cystatin C Formula. NCI Thesaurus. Code C161340.

A formula to estimate glomerular filtration rate that takes into account sex, age, race, serum creatinine (SCr) and serum cystatin C (Scys). eGFR(mL/min/1.73 m2)=135 x $\min (S C r / k, 1) a \times \max (S C r / k, 1)-0.601 \times \min (S c y s / 0.8,1)-0.375 \times \max (S c y s / 0.8,1)-0.711 \times$ $0.995^{\wedge}$ Age x 0.969 [if female] x 1.08 [if black]. (Inker LA, Schmid CH, Tighiouart H, et al. Estimating glomerular filtration rate from serum creatinine and cystatin C. N Eng IJ Med. 2012;367(1):20-29.) 